\title{
Política, cultura e posse da terra na Fazenda Machadinha
}

\section{Ana Cláudia Cruz da Silva \\ Professora do Departamento de Antropologia Universidade Federal Fluminense}

Resumo: Este trabalho está baseado em uma pesquisa de cunho etnográfico realizada na comunidade certificada como remanescente de quilombo Fazenda Machadinha, situada na região Norte do Estado do Rio de Janeiro. Tendo em vista a compra das terras pela prefeitura e o posterior reconhecimento de sua posse aos moradores através de um decreto municipal, seu objetivo é refletir sobre as limitações e implicações políticas relativas à elaboração do laudo antropológico de reconhecimento desta terra quilombola e à autonomia da comunidade nas relações travadas com o poder político local.

Palavras-chave: política; cultura; poder local; comunidade quilombola; Fazenda Machadinha. 


\title{
Politics, culture and land tenure in Machadinha Farm
}

\begin{abstract}
This paper is based on an ethnographic research conducted in Fazenda Machadinha, a remaining of quilombo community located in northern region of Rio de Janeiro state. Considering the buying of the lands by the municipal administration and the subsequent recognition of its ownership to residents through a municipal ordinance, my propose is to reflect on the constraints and political challenges when the preparation of anthropological reports about that quilombola land as well as to think about the autonomy of community in its relations with the local-level politics.
\end{abstract}

Keywords: politics; culture; local-level politics; remaining of quilombo community; Fazenda Machadinha.

\section{Política, cultura y tenencia de la tierra em la Fazenda Machadinha}

Resúmen: Este trabajo está basado en una investigación de corte etnográfico realizada en la comunidad certificada como remanente de quilombo Fazenda Machadinha, ubicada en la región norte del Estado de Río de Janeiro. Tomando en cuenta la compra de estas tierras por la prefectura y el posterior reconocimiento de la posesión de los moradores a través de un decreto municipal, su objetivo es reflexionar sobre las limitaciones e implicancias políticas relativas a la elaboración del laudo antropológico para el reconocimiento de esta tierra quilombola y a la autonomía de la comunidad en las relaciones establecidas con el poder político local.

Palabras clave: política; cultura; poder local; comunidad quilombola; Fazenda Machadinha. 


\section{Introdução}

O presente trabalho é oriundo de um projeto de pesquisa já concluído há alguns anos denominado "Antropologia da Cultura na Fazenda Machadinha Quissamã/Rj1". Seu objetivo foi compreender o uso e os significados atribuídos ao conceito de cultura pela comunidade de Machadinha e pelos agentes sociais com os quais ela se relaciona através desse conceito, produzindo, assim, uma antropologia da cultura. Nesse sentido, o conceito de cultura não pode ser entendido como um definidor de fenômenos sociais - como acontece quando nos referimos a 'aspectos', 'traços' culturais - ou um delimitador de coletividades - como quando falamos que estudamos a 'cultura tal' -, mas como um conceito polissêmico, o qual, sendo utilizado pelos mais diversos agentes sociais, apresenta também diferentes significados os quais podem ser observados em uso nas práticas sociais, ou seja, podem ser etnografados. Assim, há diferentes significados do conceito de cultura em jogo nas relações estabelecidas internamente à comunidade de Machadinha e desta com outros setores sociais, como a prefeitura, organizações não governamentais, agentes turísticos, entre outros, a partir dos agenciamentos de fluxos de ideias, políticas, economias, histórias, memórias etc. que conformam essas relações.

Neste artigo abordo um aspecto da pesquisa que diz respeito às relações da comunidade com a gestão municipal no momento da realização do trabalho de campo (2009-2012) a partir da questão do estatuto da propriedade da terra onde vive a comunidade de Machadinha e as implicações que a situação traz para a autonomia dessa comunidade. Essas questões necessariamente passam pelo conceito de cultura, o qual será alvo de uma breve reflexão analítica.

É preciso ressaltar ainda que desde o momento de realização da pesquisa houve mudanças nas relações da comunidade com a política local, as quais acompanho de longe, uma vez que não retornei ao campo depois da conclusão da pesquisa. Atualmente a comunidade interage com outros atores que não participavam da conformação social, política e econômica existente àquela altura $^{2}$, o que, suponho, vem permitindo outros arranjos. Entretanto, é possível afirmar que a reflexão trazida neste trabalho permanece válida tanto em função da situação jurídica em que permanece a comunidade no que tange à titulação das terras quanto por ser exemplo de um tipo de relação que traz informações etnográficas para pensar o nosso sistema político, o uso hierárquico e racista que pode assumir o conceito de cultura e, é claro, o que entendemos como sociedade.

\section{O lugar da Fazenda Machadinha em Quissamâ}

\footnotetext{
${ }^{1}$ Pesquisa realizada com financiamento da Fundação Carlos Chagas Filho de Amparo à Pesquisa do Estado do Rio de Janeiro - Edital APQ1 2010/o1, no período de janeiro de 2011 a junho de 2012.

2 Como exemplo, há dois anos ocorre o evento Encontro de Saberes Território Criativo - Comunidade do Quilombo Machadinha, promovido pelo Projeto Prospecção e Capacitação em Territórios Criativos UFF/MinC e pela Associação de Remanescentes de Quilombo Machadinha (Disponível em http://litoralnf.com/quissama/4312-ii-encontro-de-sabereslocais-do-quilombo-machadinha-neste-sabado-9. Acessado em 17/11/2016).
} 
Fazenda Machadinha, onde vive a comunidade de mesmo nome, é uma entre algumas fazendas remanescentes do momento áureo da economia de Quissamã, município do norte do Estado do Rio de Janeiro emancipado de Macaé, do qual era distrito, em 1989. Assim como outros municípios da região, Quissamã sempre teve a cana-de-açúcar como sua principal atividade econômica, perdendo força nas últimas décadas. Porém, seu auge ocorreu no século XIX, momento considerado tardio em relação a outras regiões (MATTOSO, 2003: 3). Exemplo disso é o casarão da Fazenda Machadinha, construído na segunda metade do XIX e que se encontra em ruínas consideradas irrecuperáveis. Quissamã é um dos municípios beneficiados com os royalties do petróleo extraído da Bacia de Campos, sendo esta sua receita mais significativa (MACHADO, 2006: 21).

Segundo o Censo Demográfico de 2010, Quissamã conta com uma população residente de 20.242 pessoas, sendo que $36 \%$ delas vivem na zona rural. Quanto à classificação de cor ou raça, ela está assim distribuída3:

População residente - cor ou raça - Branca:
População residente - cor ou raça - Preta:
População residente - cor ou raça - Amarela:
População residente - cor ou raça - Parda:
População residente - cor ou raça - Indígena:

$$
\begin{array}{r}
6.860 \text { pessoas } \\
2.126 \text { pessoas } \\
282 \text { pessoas } \\
10.961 \text { pessoas } \\
13 \text { pessoas }
\end{array}
$$

A soma da população de cor ou raça preta com a de cor ou raça parda resulta no dobro da população de cor ou raça branca, ou seja, a população quissamaense é majoritariamente negra, chegando a $64,65 \%$ do total4. Este dado em si mesmo não é significativo, mas ele ajuda a pensar o lugar da população negra - e de Machadinha, consequentemente - na configuração social de Quissamã e na imagem produzida pelo turismo.

A história oficial da cidade faz referência à presença da população negra. Ela está em sua origem e em seu nome: em 1634, "Sete Capitães" proprietários de terras na região doadas por Martim de Sá, em visita de exploração, encontraram um africano vivendo entre os índios e perguntaram de onde ele vinha, ao que respondeu que vinha da região de Kissama, situada em Angola. A partir de então, este passou a ser o nome da localidade (CORDEIRO, 2009: 63).

"O negro" é homenageado através de uma estátua, em tamanho maior que o natural, localizada na entrada da cidade. Trata-se de uma imagem de um trabalhador da cana-de-açúcar, negro, responsável pela prosperidade de Quissamã. Abaixo dele há um navio, referência à origem africana, e uma placa explicando o nome da cidade. Afora esta homenagem, Quissamã só é negra em Machadinha, isto é, quando se fala em população negra, em descendentes de escravos da região, em elementos considerados oriundos de um passado escravo e negro, as pessoas da cidade dizem que tudo vem de Machadinha, embora haja várias comunidades negras na zona rural do município e não seja pequeno o número de moradores de Machadinha que vieram de outras fazendas, hoje comunidades, nas redondezas. Entre o africano Kissama e a comunidade negra de Machadinha foi estabelecida uma relação de continuidade através de um

3 Fonte: http://www.informacoesdobrasil.com.br/dados/rio-de-janeiro/quissama/ - Acessado em 01/o5/2012.

4 Fonte: Ranking dos municípios brasileiros de acordo ao peso percentual da população preta \& parda, Brasil, 2010 Anexo ao Boletim Eletrônico “Tempo em Curso”, Ano III: Vol. 3; no. 10, Outubro, 2011. A designação 'negra' para a soma da população parda e da população preta é procedimento comum no Brasil nas análises sobre desigualdades raciais. 
Memorial instalado na comunidade onde estão expostas gravuras, objetos e fotos da região de Kissama, em Angola, trazidos pelos membros de uma "comitiva" da prefeitura que esteve lá em busca das "origens". Essa viagem e a instalação do Memorial ocorreram no momento de 'turistifacação' da comunidade, enquanto se dava a reforma das senzalas, a construção do restaurante e a organização do grupo de jongo.

Com o declínio da cana-de-açúcar e a incerteza quanto ao valor e duração dos royalties, o governo municipal viu no turismo uma alternativa econômica, tanto que ele estava vinculado à Secretaria de Desenvolvimento Econômico e Turismo, segundo me disse o secretário à época, em entrevista. Todo o investimento da prefeitura em Machadinha, sem desconsiderar os benefícios para a população, tem o turismo como fim, entendido como atividade econômica promissora para o governo e para a comunidade. O Complexo Cultural Fazenda Machadinha tem destaque nos vários materiais gráficos produzidos pela prefeitura e em seu site oficial. Além de Machadinha, os outros atrativos do turismo histórico e cultural de Quissamã são casarões de antigas fazendas do período canavieiro, alguns bastante deteriorados e outros ainda habitados - alguns deles transformados em museus e centros culturais - e alambiques também situados nessas fazendas, incluindo o da família do prefeito à época da pesquisa, irmão do secretário de Desenvolvimento Econômico e Turismo.

A restauração de alguns desses casarões começou ainda no primeiro mandato do ex-prefeito Armando Carneiro da Silva 5 visando o desenvolvimento da atividade turística. Mas não se pode perder de vista que essas propriedades pertencem a famílias que têm estado à frente do poder político e econômico de Quissamã ao longo de toda a sua história. Esses casarões são exemplos arquitetônicos do período áureo da economia canavieira e daquela distribuição de poder político. Apenas a título de ilustração, reproduzo neste trabalho a citação abaixo que sucintamente narra o início da história de Machadinha, em que se pode perceber a família Carneiro da Silva (do ex-prefeito, sobrinho do atual, o qual foi eleito para o seu quarto mandato em 2012) como primeira proprietária da fazenda. E Machadinha não é a única da região.

\begin{abstract}
As terras da Fazenda Machadinha foram adquiridas em meados do século XVIII por João Carneiro da Silva, contratador de diamantes da coroa portuguesa, que também adquiriu as terras da Fazenda do Melo e do Sítio Mato de Pipa. Após sua morte, seu filho, Manoel Carneiro da Silva tornou-se proprietário das terras e construiu um pequeno engenho de açúcar. Com o falecimento de Manoel Carneiro, a fazenda passou a ser dirigida pelo seu filho, João Carneiro, sob a tutela de seu tio, Brigadeiro José Caetano Barcelos Coutinho. Em 1798, foi inaugurado um novo engenho, demolido e reconstruído em 1803. Em 1808, João Carneiro construiu a primeira casa de moradia da Fazenda Machadinha, e em 1833, foi construída a capela. Devido à morte de João Carneiro em 1851, a fazenda foi herdada pelo seu sobrinho, Manoel Carneiro da Silva, filho do Visconde de Araruama, que tornar-se-ia Visconde de Ururai. Em 1854, Visconde de Ururai casou-se com a filha de Duque de Caxias, Ana do Loreto Viana de Lima e Silva. Em 1863, o Visconde de Ururai mandou construir a Casa Grande ou solar, sendo inaugurado somente em 1867. (MACHADO, 2006: 22)
\end{abstract}

Em Machadinha, a "casa-grande” não tem condições de ser restaurada e suas ruínas permanecem de pé graças a estruturas de sustentação que as

5 Desde sua emancipação em 1989, os prefeitos de Quissamã foram os seguintes: 1989 -1992: OCTAVIO CARNEIRO DA SILVA; 1993-1996: ARNALDO GONCALVES DA SILVA QUEIROZ MATTOSO; 1997 - 2000: OCTAVIO CARNEIRO DA SILVA; 2001-2004: OCTAVIO CARNEIRO DA SILVA; 2005-2008: ARMANDO CUNHA CARNEIRO DA SILVA; 2009 2012: ARMANDO CUNHA CARNEIRO DA SILVA; 2013-2016: OCTAVIO CARNEIRO DA SILVA. Retirado de http://www.tse.jus.br/eleicoes/eleicoes-anteriores. Acesso em 28/05/2013. 
preservam assim. No entanto, seu atrativo está na outra ponta da estrutura econômica da sociedade canavieira: as senzalas da fazenda, as quais são hoje ocupadas por descendentes de escravos que teriam permanecido nelas após o fim da escravidão. Qualquer visitante que tenha a oportunidade de conversar com alguns moradores, pelo menos com aqueles mais habituados para o trato com o turista, pode ouvi-los dizer uma espécie de jargão sobre o lugar: que lá, foram os pobres que continuaram de pé, ou seja, as senzalas, enquanto os ricos ruíram. Não vale a pena reproduzir os dados de vários pesquisadores sobre a história da fazenda 6 , basta dizer que a grande maioria dos moradores de Machadinha é de descendentes de escravos que continuaram morando na Fazenda após a abolição e ainda trabalhando com a cana, até que se tornaram trabalhadores do Engenho Central, o qual adquiriu a fazenda em 1936 (MACHADO, 2006: 24). Muitos moradores remontam sua ascendência até a escravidão na Machadinha, mas alguns poucos são descendentes de escravos de outras fazendas da mesma região que acabaram indo morar na comunidade porque se tornaram funcionários do Engenho. Por outro lado, ex-moradores de Machadinha, descendentes de escravos desta fazenda, foram morar em localidades próximas, como o Sítio Santa Luzia, Bacurau, Santa Catarina...

Em 2001, no segundo mandato de Octávio Carneiro da Silva, a prefeitura comprou uma parte da Fazenda Machadinha do Engenho Central. Trata-se da área em que estão localizadas as ruínas da casa-grande e seu entorno, com as senzalas, o antigo estábulo transformado em Casa de Artes (formado por uma loja para venda de artesanato e um restaurante) e a Capela de Nossa Senhora do Patrocínio, situada em frente a um dos arruados de senzalas. Desse entorno constam também um posto de saúde, dois campos de futebol, uma pequena escola que não estava sendo utilizada no momento da pesquisa, um salão transformado em bar e outro transformado no Memorial. Na entrada da fazenda há uma escola municipal que atende a estudantes dos dois segmentos do ensino básico moradores de Machadinha e das demais comunidades próximas. Segundo Dalmaso (2012), responsável pelo laudo antropológico de identificação das terras da Fazenda Machadinha, que fora certificada como comunidade remanescente de quilombo pela Fundação Cultural Palmares em 2006, apenas essa pequena parte da fazenda foi comprada pela prefeitura. Uma extensa área continua sendo de plantação de cana-de-açúcar e pertence à Companhia Engenho Central de Quissamã, à qual os moradores não têm acesso. Como também não têm acesso a áreas para fazer roças e criar animais.

Em 2007, Flávia Dalmaso realizou a pesquisa que resultou no laudo antropológico encaminhado ao INCRA para dar andamento ao processo de titulação das terras. Em 2008, através de decreto municipal, a prefeitura reconheceu a propriedade da área às famílias7, mas elas continuam aguardando

${ }^{6}$ Dados sobre a história da Fazenda Machadinha podem ser encontrados em Silva, 2009; Fernandes, 2008; Lamego, 1934; Melo, 2006; Dalmaso, 2012, entre outros.

7 "Decreto municipal $\mathrm{n}^{0} 1070 / 2008$ reconhece a propriedade definitiva das terras ocupadas pelos remanescentes das antigas senzalas de comunidade quilombola existente no Complexo Cultural Fazenda Machadinha." Retirado de 
a titulação das terras como comunidade quilombola pelo INCRA. E aqui se encontra uma das especificidades de Machadinha no que tange à regularização da propriedade da terra que afeta diretamente a relação da comunidade com o governo local.

$\mathrm{Na}$ época de sua pesquisa, ocorrida antes do decreto municipal de reconhecimento da propriedade definitiva das terras de Machadinha à comunidade, apenas dez casas haviam sido reformadas e entregues aos proprietários. Dalmaso (2012) informa que teve acesso a um documento emitido pela prefeitura para esses moradores e o que ele assegurava era o uso da casa pelo morador pelo período de quinze anos, não sua propriedade. É possível que o decreto municipal de 2008 tenha invalidado tal documento. As informações a respeito da situação de Machadinha são confusas. Se juridicamente a situação não tem importância em face da homologação da titulação das terras que deverá ser feita pelo INCRA, não se pode menosprezar os efeitos políticos estabelecidos nessa relação, a qual tem a questão da propriedade da terra como apenas uma de suas bases.

\section{Complexo Cultural Fazenda Machadinha}

Em meu trabalho de campo, ouvi diversas vezes de agentes ligados à prefeitura que todo o trabalho que esta exercia em Machadinha visava à geração de emprego e renda e à autonomia da comunidade no gerenciamento dos equipamentos turísticos construídos pelo governo municipal com esse fim. Ao conjunto desses equipamentos, a prefeitura deu o nome de Complexo Cultural Fazenda Machadinha. Ao mesmo tempo, essas mesmas pessoas diziam que a comunidade ainda não tinha condições de se sustentar, de gerir o restaurante e a loja de artesanato porque lhe faltava competência ou vontade de trabalhar, argumentos usados por diferentes pessoas dependendo de sua relação com a comunidade ou de sua responsabilidade política na emissão de suas opiniões. Passo agora a descrever o Complexo Cultural ressaltando a relação entre a prefeitura e a comunidade.

As ruínas da casa-grande, a capela e as senzalas foram tombadas como patrimônio histórico do Estado do Rio de Janeiro pelo INEPAC (Instituto Estadual do Patrimônio Cultural) em $1979^{8}$. As senzalas e a capela foram restauradas recentemente. Esses prédios fazem parte do que a prefeitura denomina de Complexo Cultural Fazenda Machadinha, que inclui ainda a Casa de Artes e o Memorial. A palavra "cultural” aqui se refere às práticas destacadas

http://www.museusdorio.com.br/joomla/index.php?Itemid=89\&id=55\&option=com_content\&view=article. Acesso em 29/05/2013.

8 Tombamento definitivo em 08/02/1979. Fonte: Portal do Instituto Estadual do Patrimônio Cultural. http://www.inepac.rj.gov.br/modules.php?name=Guia\&file=consulta_processo\&idprocesso=123. Acesso em 02/06/2010. 
como próprias e exclusivas dessa comunidade: o jongo, o fado ${ }^{9}$, a comida. Percebe-se também que o fato das pessoas viverem nos prédios das antigas senzalas retira do lugar seu aspecto puramente histórico. É interessante notar que nos materiais gráficos de propaganda turística de Quissamã, o roteiro que leva à Fazenda Machadinha é classificado como cultural, diferenciando-se do histórico (fazendas e casarões) e do natural (praias e Parque Nacional da Restinga de Jurubatiba). Embora o termo 'museu vivo' não seja utilizado, as propagandas turísticas produzidas pela prefeitura promovem a expectativa de que o visitante irá conhecer "descendentes de escravos que mantêm vivas as tradições do passado”. Em alguns momentos do campo foi patente a decepção de pessoas ao perceberem que a comunidade não vive cotidianamente as "tradições do passado". Apenas a título de exemplo: em uma ocasião em que o jongo se apresentou na Casa de Artes, uma mulher, depois de declarar seu "amor" ao jongo, disse que gostaria de aprender a dançar. Ela ficou visivelmente decepcionada quando perguntou em que dia da semana as pessoas se reuniam e ouviu a resposta da coordenadora do grupo de jongo de que isso só acontecia quando havia apresentação ou precisavam ensaiar para alguma que estivesse em vista.

A Casa de Artes era o estábulo da fazenda, que foi reformado e hoje abriga um restaurante e uma loja de artesanato. O restaurante funciona aos sábados e domingos oferecendo um buffet de comida caseira. A idealizadora do restaurante, Darlene Monteiro, conta, em entrevista, que o projeto previa a oferta de culinária brasileira e do Projeto Raízes do Sabor, idealizado por ela e que consiste da degustação de pratos que seriam feitos pelos escravos como forma de ter uma alimentação melhor do que aquela permitida pelos senhores, como o escondidinho (a carne escondida sob uma camada de purê de mandioca era enviada para as crianças filhas das escravas domésticas) e a feijoada, por exemplo. Entretanto, segundo fui informada, esse projeto só acontece em ocasiões muito especiais, assim, não tive a oportunidade de conhecê-lo em funcionamento. Nos finais de semana ou em feriados com previsão de fluxo turístico, o restaurante oferece pratos semelhantes à comida mineira ao preço de $\mathrm{R} \$ 26,00$ (vinte e seis reais) por pessoa em junho de 2012. O restaurante de Machadinha surgiu para ser uma fonte de geração de renda para a comunidade, por isso, ele é totalmente subsidiado pela prefeitura, que pagava nessa mesma época $\mathrm{R} \$ 32,00$ (trinta e dois reais) por pessoa. Porém, no momento da pesquisa, apenas a nutricionista e a administradora, que são brancas e moradoras da sede de Quissamã, tinham salário fixo pelo trabalho que desenvolviam no restaurante. Algumas poucas mulheres de Machadinha trabalhavam no atendimento e na cozinha, de maneira intercalada nos finais de semana e recebiam $\mathrm{R} \$ 25,00$ (vinte e cinco reais) pela diária, o que significa que cada uma delas percebia, em média, $\mathrm{R} \$ 100,00$ (cem reais) por mês. O restaurante também contribui com o grupo de jongo, que costuma se apresentar

9 Fado é uma manifestação cultural que envolve música e dança típicas afro-brasileiras, encontrada no norte fluminense, e que não guarda relações com o fado, conhecido estilo musical português. 
quando há a visita de muitos turistas levados pelas agências que pagam pelas apresentações. Mas estas são esporádicas, não consistindo em uma fonte de renda fixa.

Segundo a administradora do restaurante, há outra forma de contribuição com a comunidade: ao final de cada dia, a comida que sobra é distribuída aos moradores, que fazem fila com potes plásticos para levá-la para casa.

A loja de artesanato também deveria ser uma fonte de renda para a comunidade, mas não havia produção em Machadinha e a loja não costumava ser aberta. No único momento em que a encontrei funcionando, estavam à venda produtos de taboa feitos por pessoas moradoras de outra localidade sem nenhuma relação com Machadinha.

Em diversas oportunidades de conversar sobre o restaurante e sua função na comunidade com pessoas vinculadas à prefeitura, como a administradora e o próprio secretário, era recorrente o argumento de que os moradores de Machadinha ainda não haviam conseguido se desvencilhar da tutela do governo municipal. O passado escravo chegou a ser invocado como motivo para a suposta "falta de iniciativa", pois as pessoas seriam acostumadas a ser mandadas por brancos e por "gente de fora" e a não obedecer a outras consideradas iguais, ou seja, negras e moradoras da comunidade. Outro argumento é que a prefeitura oferece capacitação para os moradores, mas eles não se interessariam e não cuidariam do restaurante, não reconhecendo que ele lhes pertence. Não é preciso uma análise profunda para perceber que não se pode reivindicar a posse de - e dar o devido cuidado a - um lugar em que não se pode entrar quando se quer, em que não se pode realizar eventos comunitários. A Casa de Artes funciona desde 2008 e sua administração nunca foi deixada a cargo da comunidade.

O restaurante é belamente decorado com motivos e artefatos africanos, o que é coerente com a proposta do Memorial, outro prédio que faz parte do Complexo Cultural Fazenda Machadinha. O Memorial ocupa o espaço onde antes funcionava um salão comunitário dedicado a reuniões festivas: batizados, aniversários, festas religiosas, bailes de fado e forró. O único espaço de convivência entre os moradores é o armazém, que também funciona como bar, em que as pessoas - principalmente homens - se reúnem para beber. Foi unânime, entre os moradores com os quais conversei, que o antigo salão faz muita falta à comunidade, mas nenhum deles criticou a prefeitura por isso. $\mathrm{O}$ Memorial é o último prédio do primeiro bloco de casas, logo na entrada de Machadinha, lugar por onde circulam muitos moradores, mas eles não fazem uso do espaço, destinado exclusivamente ao turismo. Além das fotos e objetos trazidos de Kissama/Angola, conforme já informado anteriormente, o Memorial também apresenta a história da Fazenda Machadinha, com fotos e informações de seus antigos proprietários. Estranhei que não houvesse objetos da própria fazenda. Estranhamento que se agravou quando um dos moradores de Machadinha me mostrou vários objetos que recolheu do chão da fazenda durante as obras, como chaves das senzalas, enormes pregos de ferro, algumas 
ferramentas, entre outros. Perguntei por que eles não eram expostos no Memorial e ele me respondeu que aqueles objetos eram dele e que não iria dálos para a prefeitura. Esta fala evidencia a relação que a comunidade tem com este equipamento turístico.

O Complexo Cultural Fazenda Machadinha é uma das apostas do governo municipal no turismo quissamaense. Além da restauração do complexo arquitetônico de senzalas, capela, armazém e da construção da Casa de Artes e do Memorial, ela produziu livros (como FERNANDES, 2008; SILVA, 2009), subsidia o restaurante, fornece roupas e contrata o grupo de jongo, entre outros financiamentos em festas religiosas, eventos etc. A outra aposta é na restauração dos casarões das fazendas de cana-de-açúcar e na visitação a alambiques ${ }^{10}$.

Sem desconsiderar que as ações promovidas pelo poder público municipal em Machadinha visam o bem da comunidade, chama a atenção a configuração assumida pelo investimento em turismo histórico e cultural que vem ocorrendo em Quissamã, cujas atrações se baseiam na hierarquia social dos tempos da escravidão. Casas-grandes e senzalas estão sendo restauradas. Enquanto as primeiras pretendem contar a história da formação do município e de seu período de riqueza e prosperidade a partir dos proprietários das grandes fazendas, as segundas objetivam "resgatar" a forma de viver de um tempo passado - e se trata de um passado identificado com sofrimento e falta de dignidade -, a qual é entendida também como parte do presente, uma vez que a restauração das senzalas e a construção dos demais prédios (Casa de Artes, Memorial, restaurante) visam a "preservação" e a "manutenção" da "cultura" dessa comunidade. Como demonstram os folhetos turísticos de Quissamã, em Machadinha está a "cultura" - de outra forma de vida, já que são os outros que sempre têm cultura, nunca a "nossa" sociedade - enquanto nas fazendas, nas casas-grandes está a "história". Apesar da homenagem ao "negro kissama" e ao trabalhador nos canaviais presente na entrada da cidade, a configuração turística municipal separa quem fez Quissamã ser o que é - os grandes senhores de engenho retratados em sua história - daqueles que constituem uma vida à parte, exótica, uma cultura que pode ser observada turisticamente.

Para Melo, refletindo sobre o investimento da prefeitura em Machadinha,

é possível perceber como as práticas "tradicionais" associadas à comunidade de Machadinha cumprem um papel importante nas novas estratégias e formulações da cidade de Quissamã. Elementos da memória local estão sendo acionados com vistas à construção e valorização de um passado no qual os setores subalternos têm um papel fundamental. (2006: 100)

Penso, ao contrário, que a reprodução no turismo da hierarquia social dos tempos escravocratas não traz valorização aos setores subalternos, afinal, não há prazer algum em relembrar a escravidão. Não há dúvida de que toda essa política social e de turismo trouxe benefícios à Machadinha: as pessoas estão vivendo com mais dignidade em casas melhores, mais confortáveis, sem riscos

${ }^{10}$ Em 2011, Quissamã sediou o IV Encontro de Produtores de Cachaça, reunindo produtores da região. 
de desabamento. É claro também que o assédio de turistas, pesquisadores, agentes de movimentos sociais aumentam a autoestima e podem até trazer alguns ganhos financeiros. Mas é preciso não superestimar tais benefícios e ganhos. Foi comum ouvir agentes da prefeitura criticando que a comunidade não ganhe autonomia, não seja autossuficiente, como se fosse por falta de vontade ou competência dela a partir de tantos investimentos. O turismo em Machadinha - e mesmo em Quissamã - não é uma fonte de renda, principalmente considerando os reais ganhos que as pessoas na comunidade podem ter, os quais são extremamente baixos e atingem a pouquíssima gente.

\section{O conceito de Cultura}

'Cultura', assim como 'sociedade', 'identidade', entre outras, são palavras que, apesar de extremamente centrais para a antropologia, apresentam uma dificuldade para o trabalho antropológico: elas são usadas como conceitos (definem práticas que estudamos) ou objetos (designam o que estudamos: a cultura ou sociedade $\mathrm{x}$; a identidade y) no interior da disciplina, mas, são também utilizadas pelas pessoas que estudamos para definir o que elas fazem ou o que outras fazem. Neste último sentido, elas são conceitos nativos e, como tais, devem ser traduzidos pela antropologia a fim de tornar mais inteligíveis as experiências sociais que nos propomos a compreender.

Trata-se, pois, da adoção de uma perspectiva etnográfica em relação à cultura, no intuito de produzir uma antropologia da cultura. E já vou me adiantando que a proposta não passa pela formulação de Manuela Carneiro da Cunha (2009) de 'cultura com aspas' e 'cultura sem aspas', a primeira correspondendo ao que as pessoas dizem ser sua cultura e a segunda ao conceito antropológico e à vida das pessoas, tal como definimos o conceito. Uma antropologia da cultura deve incluir os usos que a própria disciplina tem feito do conceito, já que o uso 'nativo' nunca esteve - e não tem estado - dissociado do uso acadêmico. Desde a criação do conceito de cultura e de sua apropriação pela antropologia no século XIX, esses usos têm interagido e se produzido mutuamente. Não há porque salvaguardar o conceito de cultura antropológico das reflexões suscitadas pelas práticas atuais, o que não significa dizer que ele não serve para nada, mas é preciso refletir sobre para que ele serve, ou ainda serve. $\mathrm{O}$ fato de o conceito ser considerado por alguns como um definidor da Antropologia, diferente do que argumenta Hannerz (1996), não deve torná-lo 'intocável'. Um conceito só deve ser utilizado à medida que é capaz de fazer com que um determinado fenômeno social seja inteligível. Vários autores têm argumentado que o conceito de cultura antropológico, fortemente preso a noções como unidade, individualidade, nação, e a traços, elementos chamados de culturais, não consegue explicar os fenômenos, as relações produzidas pelas pessoas que estudamos e propõem o seu abandono.

A questão não é definir se o conceito de cultura traz efeitos benéficos ou maléficos para as pessoas que se utilizam dele. Uma antropologia da cultura objetiva saber como elas o utilizam, sendo uma de suas conseqüências refletir sobre como a antropologia deve utilizá-lo. O estudo pela antropologia dos significados que são atribuídos ao conceito de cultura por diferentes grupos 
sociais, assim como suas formas de emprego, deve produzir o que Herzfeld denomina de "reflexividade socio-cultural", que "nos permit[a] ver nossas próprias práticas culturais, com a antropologia proeminentemente incluída, num contexto comparativo" (2014: 46). Tal como argumenta Strathern a partir de sua proposta de antropologia reflexiva, conceitos são produzidos em contextos sociais específicos, "num modo cultural particular", inclusive aqueles das ciências sociais ocidentais. Como o antropólogo pertence a esse contexto, não é possível que se exclua de suas práticas, mas deve tornar visível, explícito seu funcionamento (2006: 32-3). E isso se dá através da contextualização dos conceitos nativos e da contextualização dos constructos analíticos do observador (Ibidem: 33). Trata-se de produzir uma perspectiva diferenciada entre os interesses daqueles que estudamos e os interesses da antropologia (Ibidem: 28). Questão que se torna mais difícil e delicada na medida em que observados e observadores fazem uso das mesmas palavras: os primeiros para nomear suas ações; os segundos para descrever as ações nomeadas pelos primeiros. Como diz Handler a respeito do conceito de identidade, como conceito analítico ele é diferente do conceito 'ideológico' e, se quisermos "comentar criativamente" sobre este último, precisamos de uma "outra linguagem" (1994: 30).

É preciso observar ainda que o conceito de cultura não é apenas central para a antropologia, mas também, e cada vez mais, para a sociedade que o gerou. Pelo menos desde o século XVIII ele tem designado o que é considerado mais importante para esta sociedade em seu sentido de progresso, de espírito cultivado (OVERING e RAPPORT 2000: 92) ou "cultura-valor", como define Guattari (1986: 18); e desde o nascimento da antropologia, no século XIX, por nomear a diferença para fora e no interior desta mesma sociedade, no sentido antropológico ou "cultura-alma coletiva", para o mesmo autor (Ibidem). E também não é novidade que a cultura participe do que se considera o domínio mais característico dessa sociedade, o mercado. Há tempos que se pode falar da existência de "cultura-mercadoria", ou seja, os bens culturais (Ibidem). O que talvez apareça como uma característica da nossa visão de mundo atual é a difusão da palavra cultura e sua presença, ou mais propriamente, seu embrenhamento, em domínios da vida social em que sua entrada ocorria sempre por vias marginais, como a política e a economia.

Concomitantemente à mobilização de grupos sociais a partir de diferentes concepções de cultura, temos visto, especialmente no Brasil nos mandatos do Governo Lula, a promoção de políticas dirigidas a uma variedade de práticas culturais, desde aquelas consideradas dominantes e que já possuem um público consumidor nos grandes centros urbanos, até as que buscam fazer um grupo existir, como os chamados grupos 'folclóricos', 'populares', 'periféricos' ou aqueles relacionados a uma forma de existência concebida como étnica. A quantidade de recursos financeiros e de editais para a distribuição desses recursos ganhou proporções nunca antes vistas e sua origem é variada: além dos três níveis de governo, também empresas estatais e privadas, organizações nãogovernamentais e até mesmo instituições de ensino que, por outras vias, também contribuem com esses grupos. E, especialmente entre eles, a economia e a política estão fortemente entrelaçadas com as práticas culturais. Não que isso também não ocorra nas práticas culturais chamadas dominantes acima - é claro que há aí uma economia e uma política, as quais, inclusive, fazem com que outras práticas sejam chamadas 'folclóricas', 'populares', 'alternativas' ou 'periféricas'. E, para esses grupos, a articulação entre economia e política com 
cultura tem sido obrigada - por editais, pela mídia, por agências de financiamento, entre outros atores - a passar pela noção de 'sustentabilidade', a qual envolve outras noções, como 'autonomia', 'cidadania', 'inclusão social', 'desenvolvimento' e fins semelhantes que devem, necessariamente, ser o resultado das práticas culturais e dos recursos investidos nelas, como nos mostram, por exemplo, Ruben Bayardo (2007) e Joanildo Burity (2007). Contudo, é de se esperar que aqui também se encontrem outras políticas e outras economias, as quais dizem respeito a relações com políticos e a outras formas de ganho e/ou uso de recursos financeiros, como é o caso do 'turismo cultural', cada vez mais importante para o turismo como atividade econômica.

Enquanto vários autores têm defendido conceitos de cultura que poderiam ser menos reificadores, objetificadores, o que temos visto é que as pessoas o utilizam da maneira mais 'tradicional', como produtor e/ou descritor de unidades distintas de formas de viver, com base em traços e elementos culturais. Para Herzfeld, se é verdade, como afirma Sahlins, que "estamos testemunhando um processo de larga escala de transformação estrutural: a formação de um Sistema Mundial de culturas, uma Cultura das culturas..." (2014: 50), também é verdade que o conceito de cultura ligado à ideia de nacionalismo, que é ocidental, está dominando o mundo inteiro e a antropologia tem muito a ver com isso. Então, ainda segundo Herzfeld: "Claramente, uma antropologia que trabalha contra as reificações perpetuadas pela lógica dos estados-nação [...] deve, no mínimo, colocar conceitos, por exemplo, como o de 'cultura' sob um exame historicamente fundado e crítico." (Ibidem: 71). E dessa perspectiva, como diz Guattari, cultura pode ser um conceito extremamente reacionário porque, quando nós, antropólogos, dizemos que os grupos têm cultura no sentido de 'alma coletiva', imediatamente o conceito de cultura como 'valor' - ou como "sala de ópera", segundo Wagner (2010: 54) - os classifica e os hierarquiza a partir da nossa cultura, é claro, ao mesmo tempo em que determina qual é o seu espaço possível de atuação, de interação conosco.

\section{Considerações finais}

A partir dos dados apresentados sobre a comunidade de Machadinha, podemos ver em ação os três significados de cultura tais como colocados por Guattari (1996): a cultura-valor, que separa os roteiros turísticos e atribui "cultura" à Machadinha e "história" aos casarões da elite canavieira, ou quando a administração dos bens que deveriam gerar renda, como o restaurante, é confiada a quem possui esse tipo de saber; a cultura-alma coletiva, que espera ver em Machadinha a reprodução de um modo de vida específico, exótico, capaz de atrair a curiosidade dos que possuem cultura-valor; e cultura-mercadoria, que pode ser vendida e comprada, que deve gerar renda, como as apresentações de jongo.

O conceito de cultura, então, tal como utilizado nas relações entre o poder público de Quissamã e a comunidade de Machadinha, assume um papel bastante reacionário, já que é através dele - isto é, através do que ele nomeia, define e explica como sendo cultural e, assim, próprio de Machadinha - que se 
dá o controle e se impede a autonomia da comunidade, subalternizando-a. É por sua cultura que as pessoas devem exercer tais papéis e não têm condições de exercer outros, como gerir os equipamentos turísticos existentes na comunidade, por exemplo. Também é por sua "cultura" que a prefeitura pode interferir em suas relações econômicas, de lazer (ao transformar seu salão de festas em um memorial), até de arranjos familiares: ao reformar as antigas senzalas para a habitação das famílias cadastradas, foi estabelecido um padrão de formato de casa que proíbe modificações ou construções de novos cômodos que se tornam novas moradias, solução tão comum para a população de baixa renda.

Além de toda essa relação 'tutelar' estabelecida com a comunidade no que tange ao gerenciamento de seus possíveis recursos turísticos e que, deve ser considerado, é capaz de dar emprego e renda e pouquíssimos moradores, chama a atenção outra forma de ingerência do poder municipal na vida da comunidade, pois é ele que determina que moradores ocuparão as casas. Enquanto estive fazendo pesquisa na comunidade, soube de casas fechadas, cujos moradores estavam ausentes, morando na cidade, em Quissamã, ou em outros municípios do Estado. Segundo alguns dos meus interlocutores, isso não deveria acontecer e só era possível pela conivência do poder municipal em função das relações que essas pessoas teriam com alguns políticos.

Todas essas questões são indícios da sensação de moradores e de quem pesquisa suas relações sociais de que a prefeitura é a verdadeira proprietária da comunidade, o que traz, ao menos em termos também de sensação, certa indiferença de grande parte dos moradores com os quais conversei sobre a titulação de Machadinha como comunidade remanescente de quilombo. A ausência de expectativa quanto a essa nova situação jurídica talvez seja proveniente da ideia de que não haverá mudança alguma, uma vez que os programas assistenciais direcionados a esse tipo de comunidade já são efetivos em Machadinha através da prefeitura, que fornece luz, água, cestas básicas etc. É notável também a pouca informação dos moradores quanto ao significado da comunidade ser reconhecida e titulada como remanescente de quilombo e quanto à possibilidade de autonomia que essa nova situação jurídica traria.

\section{Referências Bibliográficas}

BAYARDO, R. "Cultura y desarrollo: ¿Nuevos rumbos y más de lo mismo?” In: NUSSBAUMER, G. M. (org.). Teorias e políticas da cultura: visões multidisciplinares. Salvador, Edufba, 2007, p. 67-94.

Boletim Eletrônico Tempo em Curso, Ano III: Vol. 3; no. 10, Outubro, 2011.

Instituto Estadual do Patrimônio Cultural: http://www.inepac.rj.gov.br 
Litoral Norte Fluminense: http://www.litoralnf.com/

Portal do Instituto Estadual do Patrimônio Cultural. http://www.inepac.rj.gov.br/modules.php?name=Guia\&file=consulta_processo \&idprocesso=123. Acesso em 02/06/2010.

BURITY, J. "Cultura e desenvolvimento". In: NUSSBAUMER G. M. (org.). Teorias e políticas da cultura: visões multidisciplinares. Salvador, Edufba, 2007, p. 51-65.

CARNEIRO DA CUNHA, Manuela. Cultura com aspas e outros ensaios. São Paulo, Cosac Naify, 2009.

CORDEIRO, Wellington. "Em busca de uma africanidade”. In: SILVA, Leonardo de Vasconcellos (org.). Machadinha: origem, história $e$ influência. Quissamã/RJ, EDG Editora Gráfica, 2009, p. 62-71.

DALMASO, Flavia Freire. "Relatório Antropológico da Comunidade de Machadinha/RJ”. In: O'DWYER, Eliane Cantarino (org.). O fazer antropológico e o reconhecimento de direitos constitucionais. O caso das terras de quilombo no Estado do Rio de Janeiro. Rio de Janeiro, E-papers Serviços Ltda, 2012, p. 311-351.

FERNANDES, Raquel. Tidinho: o menino contador de histórias. Uma outra versão da história de Quissamã. Ilustrações de Wellington Carvalho. Quissamã, 2008.

GUATTARI, Félix e ROLNIK, Sueli. “Cultura: um Conceito Reacionário?” In: Micropolítica. Cartografias do Desejo. Petrópolis: Vozes, 1996, p. 15-24.

HANDLER, Richard. "Is 'identity' a useful cross-cultural concept?" In: GILLIS, John K. (org.). Commemorations. The Politics of National Identity. Princeton University Press, Princeton, 1994, p. 27-40.

HANNERZ, Ulf. Transnational Connections. Culture, People, Places. Routledge, London/New York. 1996.

HERZFELD, Michael. Antropologia. Prática Teórica na Cultura e na Sociedade. Petrópolis/RJ, Vozes, 2014.

INFORMAÇÕES

DO

BRASIL:

http://www.informacoesdobrasil.com.br/dados/rio-de-janeiro/quissama/ Acessado em 01/05/2012.

LAMEGO, Alberto Ribeiro. A Planície do Solar e da Senzala. Rio de Janeiro, Livraria Católica, 1934.

MACHADO, Fábio da Silva. Fazenda Machadinha: Memória e Tradições Culturais em uma Comunidade de Descendentes de Escravos. Dissertação de Mestrado. Programa de Pós-Graduação em História Política e Bens Culturais. 
Fundação Getúlio Vargas, $2006 \quad$ (Disponível em http://virtualbib.fgv.br/dspace/handle/10438/2115).

MATTOSO, Guilherme de Queirós. A festa do Fado de Quissamã. Biblioteca On-line de Ciências da Comunicação. 2003 (Disponível em: http://www.bocc.uff.br/pag/mattoso-guilherme-festa-do-fado.pdf).

MELO, Ricardo Moreno. Tambor de machadinha: devir e descontinuidade de uma tradição musical em Quissamã. Dissertação de Mestrado. Programa de Pós-Graduação em Música. Universidade Federal do Estado do Rio de Janeiro, 2006 www.cipedya.com/web/FileDownload.aspx?IDFile=159517).

SILVA, Leonardo de Vasconcellos (org.). Machadinha: origem, história e influência. Quissamã/RJ, EDG Editora Gráfica, 2009.

Prefeitura de Quissamã: http://www.quissama.rj.gov.br.

Tribunal Superior Eleitoral: http://www.tse.jus.br/eleicoes/eleicoes-anteriores. Acesso em 28/05/2013.

STRATHERN, Marilyn. O Gênero da Dádiva. Problemas com as mulheres e problemas com a sociedade na Melanésia. Campinas, Editora da Unicamp, 2006.

WAGNER, Roy. A Invenção da Cultura. São Paulo, Cosac Naify, 2010.

Recebido em 20/11/2016. Aprovado em 10/12/2016. 